DOI 10.5216/ia.v46i3.68429

\title{
O NARRAR SOBRE SI E A ESCREVIVÊNCIA: O LUGAR DA ESCRITA AUTOBIOGRÁFICA EM PESQUISA SOBRE FORMAÇÃO DE PROFESSORAS NEGRAS
}

\author{
RenAtA MeLo Rocha \\ Universidade Federal Rural do Rio de Janeiro (UFRRJ), Nova lguaçu, Rio de Janeiro, Brasil \\ Patrícia Bastos de AzEVEDo \\ Universidade Federal Rural do Rio de Janeiro (UFRRJ), Nova Iguaçu, Rio de Janeiro, Brasil
}

\begin{abstract}
Resumo: O presente artigo tem como escopo refletir sobre as contribuições da escrita autobiográfica para o processo formativo de futuras pedagogas negras, a partir da análise de escolhas metodológicas da dissertação de mestrado de uma das autoras. Assim, discute-se como o ato de alinhavar o ateliê biográfico de projetos, de Delory-Momberger (2006), ao termo escrevivências de Conceição Evaristo (2006), contribui para formação de professoras negras, tendo como aporte para tal reflexão alguns indícios da referida pesquisa. Nela, estudantes negras do curso de Pedagogia da Universidade Federal Rural do Rio de Janeiro são convocadas a narrarem suas trajetórias formativas através do ato de biografaremse, subvertendo a ordem, em um processo intrinsecamente formativo. Depreendese, portanto, que a escolha por tais percursos metodológicos configura-se como também espaço de denúncia, uma vez que se desenvolve no intento de desvelar memórias subterrâneas. No movimento de escrever sobre si, pedagogas negras em construção escrevem sobre memórias ancestrais, por tanto tempo silenciadas, que insurgem, em espaço de pesquisa, através da escrevivência.
\end{abstract}

Palavras-chave: Narrativas Autobiográficas. Escrevivências. Memórias Subterrâneas. Formação de Professoras Negras.

\section{INTRODUÇÃO}

Muito tem sido discutido sobre as questões raciais no Brasil, sobretudo no que diz respeito às mulheres negras, que são discriminadas por sua raça, gênero e classe social. É uma discussão atual que nos convoca a pensar sobre o protagonismo de tais narrativas e da urgência em se fazer pesquisa em educação a respeito de tal temática. Sabemos que tornar-se pedagoga na contemporaneidade perpassa por múltiplos atravessamentos, sejam eles de natureza étnico-raciais, de gênero, sexualidade dentre outros. Nesse sentido, o presente artigo anseia por compreender como escolhas metodológicas pautadas na biografização de mulheres negras podem se conjugar com pesquisas sobre formação de professoras.

O título 'O narrar sobre si e a escrevivência: o lugar da escrita autobiográfica em pesquisa sobre formação de professoras negras' anuncia o intento das autoras em aproximar metodologias pautadas em narrativas autobiográficas à escrevivência, compreendendo as imbricações de tal aproximação em pesquisas qualitativas sobre formação. $O$ trabalho concebe o conceito de narrativa autobiográfica ${ }^{1}$ como uma 
hermenêutica da experiência, isto é, um processo de formação em ação. Logo, a escrevivência é trazida pelas autoras por ser um importante e contemporâneo recurso literário, utilizado por mulheres negras. Por meio da escrevivência são escritos textos repletos de vivências e ancestralidade que ora assumem caráter ficcional, como em obras de Conceição Evaristo, ora traduzem na primeira pessoa histórias autorais, como em alguns trechos que traremos mais adiante.

Debruçaremo-nos sobre as escolhas metodológicas realizadas na feitura da pesquisa de dissertação de mestrado de uma das autoras, salientando que não iremos nos ater à completude da pesquisa, tendo-a apenas como pano de fundo para reflexões. Os caminhos metodológicos que orientaram a pesquisa supracitada deram-se pelo fato de a mesma ter como lócus a discussão sobre formação de professoras, em uma perspectiva de investigação processual e qualitativa. Assim, foi utilizado o ateliê biográfico de projetos de Delory-Momberger (2006) para encaminhamento inicial da pesquisa, organização dos encontros e produção de escritos autobiográficos e posteriormente a compreensão de tais escritos como escrevivências, termo cunhado por Conceição Evaristo (2006) para tratar sobre escritas de vida de mulheres negras.

A pesquisa, sobre a qual faremos referência, não tinha inicialmente a pretensão de abordar questões étnico-raciais e de gênero. Contudo, as narrativas das participantes compunham-se de textos repletos de vivências, memórias ancestrais e críticas sociais, tornando-se inadiável refletir sobre tais questões. Logo, fora identificado que as narrativas de si das estudantes da pesquisa tratavam-se de escrevivências, uma vez que estavam marcadas pela condição de mulher negra. Conceição Evaristo (2006) chama tais escritas de escrevivências, em um neologismo que 'brinca' com os verbos 'escrever' e 'viver'. Apesar da gênese do termo escrevivência, Conceição Evaristo salienta que diversos grupos e sujeitos podem se apropriar do termo para narrarem suas histórias, desde que o reconheçam enquanto instrumento de luta e resistência do feminino negro no Brasil.

No primeiro tópico iniciaremos nossas reflexões a partir de inferências acerca de como se dá a narrativa de si no ateliê biográfico de projetos ${ }^{2}$. Para tanto, serão apresentados eixos do ateliê, utilizados na pesquisa supracitada, com o intuito de melhor compreender as etapas de tal percurso metodológico. Esta metodologia resulta na produção de escritos autobiográficos que revelam não apenas o passado, mas, também o desejo pessoal de cada um em ler a si mesmo a partir do movimento de recuperação das memórias. Essas lembranças são trazidas inicialmente de forma caótica, mas o sujeito dá conta de apresentá-las de maneira organizada, atribuindo-lhes sentido. Portanto, as escritas autobiográficas não são a representação fiel do passado e sim uma releitura do vivido, sob a ótica de seu narrador, que, como sujeito sócio-histórico, situase em tempo e espaço bem definidos.

É no sentido de conceber as narrativas de mulheres negras como memórias subterrâneas, isto é, compostas por marcas ancestrais em uma escrita no presente impregnada de passado, que discutiremos no segundo tópico o termo escrevivência. Em Becos da Memória, Conceição Evaristo (2006) faz uso de tal projeto literário e intelectual como uma crítica biográfica, escrevendo suas memórias e a de tantas outras mulheres negras que compõem sua trajetória, através de uma autobiografia ficcional. Assim, 
ROCHA, R. M.; AZEVEDO, P. B. de.

Conceição Evaristo inspira e traz para academia uma literatura encharcada por memórias subalternizadas pelo patriarcado e que encontram lugar para incitar no presente uma reflexão social sobre a mulher negra.

No último tópico trataremos sobre como as escolhas metodológicas por escritas autobiográficas repercutem na pesquisa sobre a formação de professoras negras, apresentando alguns fragmentos de escrevivências da pesquisa de mestrado de uma das autoras. A partir de tais recortes, refletiremos como os atravessamentos compõem os percursos formativos dessas pedagogas negras e a importância de tais indícios para o desenho de pesquisas que fomentem o diálogo com pedagogas em construção. Vale ressaltar que não iremos nos ater à análise dos indícios presentes em tais escrevivências. Eles serão apresentados com o objetivo de identificarmos a multiplicidade de tessituras que decorrem das escritas singulares das educadoras em formação.

Construir-se pedagoga não ocorre da noite para o dia, nem tampouco se aprende a ser educadora apenas nos bancos universitários. As análises e discussões aqui desenvolvidas anseiam por provocar inquietudes e incomodar. A importância de utilizarmos tais escolhas metodológicas para compreender a composição de educadoras negras na universidade consiste na insurgente ação de trazer à tona memórias antes contadas numa perspectiva ocidentalista e silenciadora, em uma escolha política pelo diálogo, pela escuta e pelo protagonismo de mulheres negras na educação.

ATELIÊ BIOGRÁFICO DE PROJETOS: A TESSITURA DO VIVIDO EM UMA LEITURA DE MIM E DO OUTRO ATRAVÉS DO DISCURSO

O ateliê biográfico de projetos é definido por Delory-Momberger (2006) como um procedimento que pode ser utilizado no campo universitário ou profissional e tem como objetivo inscrever a história de vida em uma dinâmica prospectiva que liga o passado, o presente e o futuro do sujeito, fazendo emergir um projeto pessoal. A autora salienta a importância dessa metodologia como espaço-formação, já que, ao narrar-se, o sujeito interpreta-se e reelabora-se, evocando memórias e experiências, numa possibilidade de leitura de si e de projeção para o futuro.

Narrativa e memória são dois pilares para o ateliê biográfico de projetos. A narrativa é a centralidade do ateliê, já que nela são traduzidas as memórias. Entretanto, é fundamental destacarmos que a vida contada não é a vida, isto é, que o que é narrado não constitui e não recupera o vivido. Nesse sentido Delory-Momberger (2006) afirma:

\footnotetext{
Nenhuma prática de formação pode pretender reconstituir por si só o que seria o curso factual e objetivo do vivido; o 'objeto' sobre o qual trabalham as linhas de formação pelas histórias de vida não é, portanto, 'a vida', mas as construções narrativas que os participantes do grupo de formação elaboram, pela fala ou pela escrita, quando são convidados a contar suas vidas (DELORYMOMBERGER, 2006, p.362).
}

Além disso, a narrativa é um objeto da linguagem que se constitui no momento de sua enunciação. Por conseguinte, ela não está fechada e limitada. Ao contrário, a narrativa de acordo com Delory-Momberger (2006) 'é uma matéria instável, transitória, viva, que se recompõe sem cessar no presente do momento em que ela se anuncia'. A 
autora destaca que mais importante que a história narrada é a compreensão de si que o sujeito faz ao construir essa narrativa. Ele mergulha em seu emaranhado de lembranças e memórias e narra a versão que melhor o traduz diante de tais experiências. DeloryMomberger (2006) infere que:

\begin{abstract}
Nesse sentido, não é tanto a história da vida reconstruída que importa em si, mas sim o sentimento de congruência experimentado entre o eu - próprio e o passado recomposto, a impressão de conveniência que essa história toma para mim no aqui e agora de sua enunciação. Ela é a história que eu me atribuo e na qual eu me reconheço, é a que me convêm e à qual eu convenho, a versão 'suficientemente boa'(DELORY-MOMBERGER, 2006, p.362).
\end{abstract}

Delory-Momberger (2006) salienta a importância da narrativa na existência humana quando a define como o lugar onde o indivíduo elabora e experimenta sua história de vida. Os acontecimentos que constituem nossa história de vida estão soltos, agregados a outras tantas memórias que o ato de narrar organiza, ancora, dá sentido, conclui. Desse modo, o sujeito faz uma releitura de si mesmo como destaca DeloryMomberger (2006):

O Eu atualizado do discurso é a forma primeira na qual se institui o sujeito: é o Eu que me inscreve ao mesmo tempo como sujeitonarrador e como sujeito-ator da história, que eu conto sobre mim mesmo. Ficção necessária e sempre renovada, o sujeito é essa figura flexível e variável ao qual é dado se compreender como autor de sua história e de si próprio (DELORY-MOMBERGER, 2006, p.364).

Já a memória traduzida pela narrativa, trata-se de uma construção coletiva e social, sendo incompleta, parcial e também mutável. Para que as memórias possam ser organizadas, Halbwachs (2006) afirma que é necessário que haja uma padronização de tempo e espaço, a fim de que exista a construção de uma coesão social, isto é, construção de memórias que representem um grupo e que sejam fundamentais para criação de uma identidade coletiva. Dessa forma, a memória não é algo que vive no passado. Ao contrário, a memória coletiva envolve e permanece viva nas pessoas no tempo presente, constituindo o que são individualmente e coletivamente. Logo, muito daquilo que recordamos e concebemos como parte de nossas memórias é construído com base nos relatos de terceiros, dependendo dos testemunhos de outros para ser concebido e formatado. Halbwachs (2006) infere:

Nossas lembranças permanecem coletivas e nos são lembradas por outros, ainda que se trate de eventos em que somente nós estivemos envolvidos e objetos que somente nós vimos. Isto acontece porque jamais estamos sós. Não é preciso que outros estejam presentes, materialmente distintos de nós, porque sempre 
ROCHA, R. M.; AZEVEDO, P. B. de. levamos conosco certa quantidade de pessoas que não se
confundem (HALBWACHS, 2006, p.30).

Além das narrativas do vivido, o ateliê biográfico fundamenta-se em oportunizar um projeto de futuro, isto é, um 'projeto de si' em que constem elementos ainda não vividos, mas já presentes no desejo dos sujeitos. Esse projeto de si não é algo consciente com detalhamento de metas, mas sim uma orientação para o futuro, que naturalmente vai sendo desenhada pelo sujeito ao longo da reconstrução de sua história nos escritos autobiográficos. Ao elaborar sua narrativa, o ateliê biográfico de projetos fomenta que o sujeito vislumbre aquilo que pode ser futuramente, deixando emergir potencialidades projetivas, compreendendo a vida como uma experiência essencialmente formadora.

Sobre a organização do ateliê biográfico de projetos, Delory-Momberger (2006) afirma que o ideal é que seja organizada em um grupo que não ultrapasse o número de doze pessoas. Todos os participantes deverão estar cientes dos temas de cada encontro, assim como de suas sinopses/roteiros e etapas principais.

As duas primeiras etapas constituem-se em familiarizar o grupo às informações dos procedimentos metodológicos do ateliê, com detalhamento das 'regras de segurança'. Essas regras falam em linhas gerais sobre a responsabilidade pelo que é dito e ouvido nos encontros e da necessidade de engajamento do grupo para que as memórias socializadas objetivem fim formativo e não terapêutico. Sobre isso, DeloryMomberger (2006) delineia:

Desde essa primeira fase são notificadas as regras de 'segurança' visando responsabilizar cada um sobre o uso que faz de sua palavra e sobre o seu grau de engajamento. Trata-se de uma palavra social, conscientizada na relação com o outro, e o formador deve chamar a atenção sobre as emoções que acompanham certas atividades autobiográficas, a fim de evitar 'derrapagens' de ordem terapêutica que desequilibrariam o grupo e o fariam sair de seu quadro de funcionamento e de sua finalidade. A animação do grupo consiste aqui em administrar as 'entradas em contato' com as emoções e apelar para a co-responsabilidade do conjunto dos participantes no que diz respeito à explosão afetiva e emocional. É transmitida uma regra de discrição e reserva sobre tudo o que será contado no interior do ateliê (DELORY-MOMBERGER, 2006, p.366).

Ainda na etapa inicial existe a ratificação coletiva do contrato biográfico no qual os sujeitos confirmam sua participação depois que o formador estipula todas as regras, datas, horários e moldes de como os encontros acontecerão. Esse contrato pode ser oral $^{3}$ ou escrito e precisa ser detalhado e aceito pelos participantes. É nesse momento que se firma com os sujeitos o viés do ateliê como metodologia autoformadora, enfatizando a responsabilidade que cada participante precisa ter consigo e com o seu grupo. Afinal, a história de cada um será socializada e a importância da palavra é essencial para que a metodologia seja bem-sucedida.

As próximas etapas destinam-se aos momentos de escrita dos relatos autobiográficos. Esses momentos alternam a escrita de si (individual) com momentos de socialização da escrita de si por outro sujeito. Inicialmente, os sujeitos produzem a 
primeira narrativa, que é individual e será retomada posteriormente na última etapa. Depois os encontros passam a ser estruturados em tríades. A organização dos sujeitos em tríades é uma marca importante do ateliê biográfico que fomenta a socialização das histórias vividas e de suas ressignificações. Nessas tríades sempre haverá um narrador, um escriba e um ouvinte.

Figura 1 - Esquema das tríades no ateliê biográfico de projetos

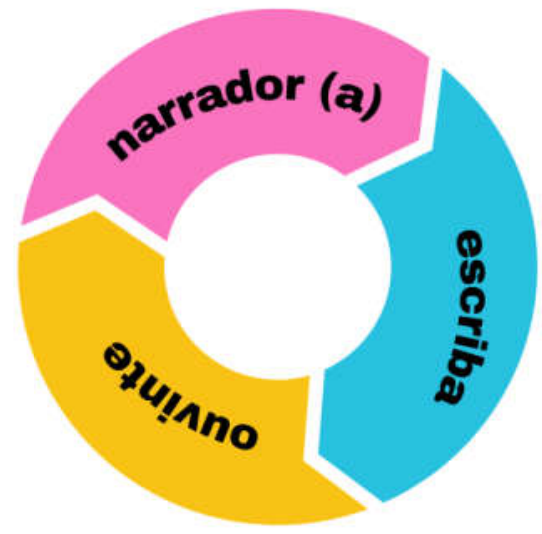

Fonte: Produção das autoras.

Os membros de uma mesma tríade interagem a todo o momento enquanto uma narrativa está sendo socializada, e cabe ao escriba registrar a narrativa. Ao fim do encontro o escriba redige um texto em primeira pessoa daquilo que foi contado pelo narrador. Sobre esse movimento de distanciar-se da própria história e ao mesmo tempo aproximar-se da história de outro alguém, Delory-Momberger (2006) infere:

\begin{abstract}
O trabalho de reescrita, por um terceiro, inscreve-se novamente na perspectiva de coerência narrativa, acima enunciada, e 'objetiva' aos olhos de seu autor/ator a 'história de sua vida'. O percurso de apropriação de sua história, que é comum ao conjunto de práticas de histórias de vida, passa aqui pela busca compreensiva do outro e o distanciamento de si mesmo (DELORY-MOMBERGER, 2006, p. 367).
\end{abstract}

Após o momento da tríade, cada participante é convocado a escrever seu relato autobiográfico final, sem exigências de tamanho ou forma, recuperando todos os escritos produzidos ao longo do ateliê e fazendo uma projeção para seu futuro pessoal e/ou profissional (dependendo do objetivo a ser alcançado). Este texto é retomado no último encontro nas tríades e depois socializado com todos. Delory-Momberger (2006) sugere que após um mês haja um novo encontro entre os participantes para que façam um 'balanço' a respeito dos projetos de si, assim como sobre os impactos do ateliê no traçado de vida de cada um. 
ROCHA, R. M.; AZEVEDO, P. B. de.

$\mathrm{Na}$ dissertação de mestrado, aqui referida como pano de fundo para que compreendamos o uso de escritas autobiográficas em pesquisa sobre formação de professoras negras, foram utilizados aspectos metodológicos do ateliê biográfico de projetos. Isso significa que há apropriação de procedimentos do ateliê biográfico de projetos e não de toda a sua metodologia, sendo possível identificar elementos próprios, construídos pela autora.

A escolha pelo ateliê biográfico deu-se pela organização proposta em sua estrutura e as possibilidades de leitura e escrita de si e do outro ao longo de toda a dinâmica. Essa organização possibilita que o material construído seja composto por um 'vai e vem' nas memórias, em uma construção do discurso impregnado de passado, mas redigido no presente. Dessa maneira, propicia-se também um movimento formativo, uma vez que as participantes podem ler suas trajetórias, identificando fragilidades e potencialidades e, mais adiante, podem também traçar em seus escritos uma projeção de si para o futuro.

As nove participantes da pesquisa supracitada foram, assim como sugere o ateliê biográfico de projetos, apresentadas a um termo de participação que ratificou a confidencialidade dos encontros e escritos para uso de pesquisa e demais desdobramentos. Conheceram as dinâmicas dos encontros e montaram tríades, escolhidas aleatoriamente, mantendo-se sob a mesma estrutura até o fim da pesquisa, de maneira que a cada novo encontro os sujeitos retomassem a socialização de suas memórias de forma progressiva e adquirissem cada vez mais confiança no grupo e na responsabilidade relacionada às próprias memórias e às memórias do outro. Cada encontro foi nomeado de acordo com o momento formativo a que se quisesse rememorar, sendo idealizados em uma sequência cronológica, no intuito de que as participantes fossem convocadas a recordarem gradativamente cada etapa de suas vidas. Portanto, de um total de quatro encontros, os dois primeiros foram responsáveis por recuperar memórias do princípio da escolarização, o terceiro encontro rememorou a escolha pela Pedagogia e os movimentos que as levaram à carreira e o último foi destinado à entrega da escrita final, composta pela congruência dos escritos de todos os encontros, acrescidos de uma projeção profissional para o futuro.

Figura 2 - Exemplo de esquema de encontros realizados com base em aspectos metodológicos do ateliê biográfico de projetos

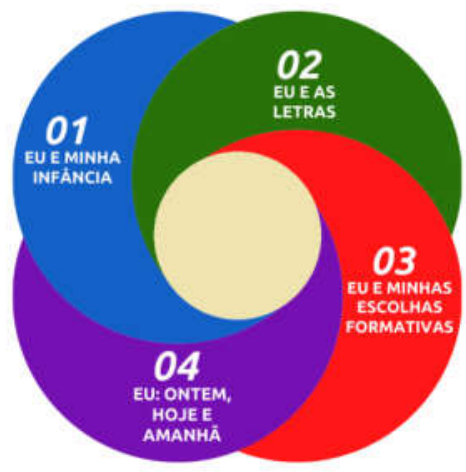

Fonte: Produção das autoras. 
É importante ressaltar que todos os encontros seguiram a partir do que DeloryMomberger (2006) intitula como script, isto é, um roteiro que direciona os relatos de memória acerca de cada uma das etapas da vida. Cada encontro era composto por um roteiro que rememorava etapas formativas específicas. No primeiro encontro, por exemplo, foi seguido o seguinte roteiro: Quem é você? Quando e onde você nasceu? Por que você tem esse nome? Como é sua família? O que você queria ser quando pequena? Sua família sonhava com alguma profissão para você? Quando começou a estudar? Você se recorda de algum fato marcante em sua infância? Após os relatos, a escriba realizava a leitura do escrito contado pela narradora, desencadeando um novo diálogo na tríade.

Deve-se ter em vista, ainda, o caráter formativo das construções autobiográficas produzidas ao longo dos encontros do ateliê biográfico de projetos ${ }^{4}$. A própria organização das dinâmicas do ateliê propicia que as memórias sejam convocadas e socializadas com os demais participantes. Logo, tal percurso metodológico constitui-se como um potente momento formativo, posto que: (i) convoca o sujeito a avaliar sua trajetória e seus atravessamentos; (ii) possibilita que haja uma interação com demais sujeitos e suas histórias; (iii) viabiliza uma projeção pessoal e/ou profissional para o futuro.

A análise de tais escritos autobiográficos, que mais adiante aproximamos ao termo escrevivências, configura-se como uma importante e valiosa investigação de discursos. Discursos esses que são compostos por muitos dizeres, uma vez que "todos os enunciados constituem-se a partir de outros" (FIORIN, 2008, p.30). Dessa maneira, operamos com um conceito bakhtiniano chamado dialogismo, que em linhas gerais, descreve que os enunciados estão impregnados de diferentes vozes sociais, com as quais os sujeitos interagem em seus cotidianos. Portanto, os discursos são sempre históricos e dizem respeito a sujeitos pertencentes a um determinado tempo e espaço social. De acordo com Bakhtin (1979):

\footnotetext{
Nossa fala, isto é, nossos enunciados (...) estão repletos de palavras dos outros. (Elas) introduzem sua própria expressividade, seu tom valorativo, que assimilamos, reestruturamos, modificamos. (...) Em todo o enunciado, contanto que o examinemos com apuro, (...) descobriremos as palavras do outro ocultas ou semi-ocultas, e com graus diferentes de alteridade (BAKHTIN,1979, p. 314/318).
}

Interessam-nos nessa discussão os atravessamentos que compõem os discursos produzidos nessas escritas autobiográficas e, por esse motivo, faz-se relevante que ressaltemos a interseção de histórias e vivências. Uma vez que aquilo que construo enquanto escrito autobiográfico não é apenas um discurso meu, quais são os outros discursos que compõem minha história? Evaristo (2006), em Becos da memória, recupera trechos de sua infância, por meio de uma personagem chamada Maria Nova, a quem muito se assemelha. Em diálogos sobre a obra, Conceição Evaristo afirma que muito da personagem diz respeito à memória de sua mãe, haja vista as lacunas presentes nas memórias da autora. Assim, Evaristo (2006) apropria-se da memória de sua mãe e tantas outras mulheres negras, assim como nós, nos ancoramos nas memórias e 
ROCHA, R. M.; AZEVEDO, P. B. de.

discursos de outrem para que possamos remontar nossas trajetórias. É sobre esses atravessamentos que refletiremos no próximo tópico.

\section{AS ESCREVIVÊNCIAS: A PRESENÇA DAS MEMÓRIAS SUBTERRÂNEAS NA ESCRITURA AUTOBIOGRÁFICA}

O conceito de escrevivência foi cunhado por Conceição Evaristo em sua dissertação de mestrado em 1994 pela Pontifícia Universidade Católica do Rio de Janeiro. Mais adiante, em Becos da Memória, Evaristo (2006) exercita o projeto literário e intelectual da escrevivência, trazendo para o debate no presente vivências ancestrais de mulheres negras. Trata-se, portanto, de uma escrita permeada por discussões no que se refere ao gênero e à raça. $A$ escrevivência de Conceição Evaristo é marcada pelo seu lugar de fala, isto é, são suas vivências de mulher negra, mãe, professora, pesquisadora e favelada da extinta comunidade de Pindura Saia em Belo Horizonte, Minas Gerais, que marcam seus escritos. Em suas obras Conceição Evaristo atua como griot - guardião da tradição oral, dos mitos e lendas africanas de povos que se sustentaram ao longo da história através da oralidade e da memória. Em um determinado trecho de Becos da Memória, Evaristo (2006) cita como as memórias daquelas e daqueles que conviveram com ela se amontoaram dentro de si, marcando sua trajetória:

\footnotetext{
(...) a recordação daquele mundo me traz lágrimas aos olhos. Como éramos pobres! Miseráveis talvez! [...] escrevo como uma homenagem póstuma [...] Homens, mulheres, crianças que se amontoaram dentro de mim, como amontoados eram os barracos de minha favela (EVARISTO, 2006, p. 29-30).
}

A escrevivência representa lugar de pertencimento e de denúncia, intimamente ligada à consciência de 'negritude', em uma militância antirracista que invade o espaço acadêmico. É o poder da enunciação de mulheres negras que foram, por séculos, alijadas de suas histórias. Nesse sentido, repousa no termo escrevivência a responsabilidade de questionar o que está posto, fazendo emergir histórias até então desprezadas e subalternizadas. Trata-se de um movimento decolonial, que valoriza as histórias locais femininas e suas sensibilidades biográficas, em uma transgressão epistêmica.

O sociólogo Michael Pollak (1989) infere como sendo 'memórias subterrâneas' aquelas pertencentes a grupos marginalizados que foram silenciados e minimizados na construção da memória nacional. Nesse sentido, Pollak (1989) ressalta:

Ao privilegiar a análise dos excluídos, dos marginalizados e das minorias, a história oral ressaltou a importância de memórias subterrâneas que, como parte integrante das culturas minoritárias e dominadas, se opõem à "memória oficial", no caso a memória nacional (POLLAK, 1989, p. 8).

O conceito de memórias subterrâneas de Pollak (1998) coaduna-se com escrevivências, uma vez que são essas memórias também instrumento de luta e discussão sobre a diáspora negra. São narrativas de si que recuperam a história daquelas que saíram das senzalas para ocuparem a contemporaneidade em uma sociedade 
marcada pelo patriarcado branco. Conceição Evaristo afirma em boa parte de suas entrevistas que dessa vez as mulheres negras não estão contando histórias para 'ninar os da casa-grande'. Ao contrário disso, contam histórias para incomodar seus sonos injustos, escancarando a realidade da vivência de mulheres negras através de dizeres de mulheres negras. Sobre isso, Evaristo (2007) ressalta como sendo a essência da escrevivência:

(...) creio que a gênese de minha escrita está no acúmulo de tudo que ouvi desde a infância. $O$ acúmulo das palavras, das histórias que habitavam em nossa casa e adjacências. Dos fatos contados a meia voz, dos relatos da noite, segredos, histórias que as crianças não podiam ouvir. Eu fechava os olhos fingindo dormir e acordava todos os meus sentidos. O meu corpo por inteiro recebia palavras, sons, murmúrios, vozes entrecortadas de gozo ou dor dependendo do enredo das histórias (EVARISTO, 2007, p. 19).

Assim, destacamos no projeto literário da escrevivência sua capacidade de tocar aqueles que a leem, rememorando também no leitor suas lembranças. Esse é um fenômeno valioso, haja vista que são essas subjetividades que aproximam o leitor das palavras e, portanto, das histórias antes não contadas. Em tempos sombrios de silenciamento é que se torna inadiável que compreendamos cada vez mais como os usos de caminhos metodológicos autobiográficos contribuem para pesquisas acerca da formação de professoras negras, em uma abordagem qualitativa de suas histórias.

\section{O USO DE ESCREVIVÊNCIAS NO PERCURSO METODOLÓGICO DE INVESTIGAÇÃO: AS TRAJETÓRIAS DE FORMAÇÃO DE PROFESSORAS NEGRAS}

Pesquisas que tenham como abordagem metodológica o uso de escritas autobiográficas diferenciam-se por serem intrinsecamente compostas pelo protagonismo daquelas que contam suas histórias. São pesquisas que ao invés de falar sobre escolhem politicamente falar com. E tal prerrogativa diz muito sobre o que a pesquisa encontrará pelo caminho, delineando uma marca qualitativa.

Tomaremos como ancoragem para reflexões acerca dos usos de metodologias autobiográficas alguns fragmentos de escrevivências utilizados na dissertação de mestrado de uma das autoras. Tais fragmentos ressaltam como a referida pesquisa escolheu falar sobre a potência das vozes de mulheres negras através das vozes de mulheres negras, como exemplifica o trecho da escrevivência em que uma das participantes se apresenta: ['sou 7a filha, nascida de parto normal, em casa com parteira, como era de costume na época em que nasci'].

Quando convocadas as memórias sobre o princípio da escolarização, muitas lembranças emergiram sobre a primeira professora, sobre a sala de aula, o chão, o teto, os medos, o prazer... Muitas escrevivências assemelhavam-se a outras do grupo e era possível enxergar como algumas histórias estavam dentro de outras de uma maneira peculiar e plural ao mesmo tempo. Três participantes detalharam terem sido alfabetizadas em escolas não-formais. Eram casas improvisadas com carteiras, mesas e 
quadro negro. A professora era intitulada como tal, pela comunidade, haja vista que detinha o 'saber das letras e dos números' para fazer aprender os pequenos da região: ['Lembro-me de Dona Maria ... no ano de 1981 e que havia bancos compridos que ladeavam uma mesa grande']. Em trechos como esse, podemos refletir sobre a história de um país que vem engatinhando no que diz respeito à oferta de educação de qualidade a todas e todos e principalmente às meninas negras e aos meninos negros de periferia. Além de tal denúncia, o trecho nos faz pensar na história da formação de professores no Brasil, na presença majoritariamente feminina no magistério e na importância das narrativas de professoras negras para construção de uma sociedade antirracista. São múltiplos indícios que convocam a uma reflexão social, ao tempo que fomentam outros atravessamentos inerentes ao 'tornar-se pedagoga'.

Em um trecho sobre a escolha pelo magistério, uma escrevivência traz um belo registro: ['Meus pais só estudaram até a $2^{\text {a }}$ série primária, mas mesmo assim aprendi muito com a minha mãe, que adorava ler e contar história para os filhos. Minha mãe me ensinava a tabuada enquanto lavava as roupas no tanque']. Neste fragmento identificamos como as vivências impactaram a escolha por ser professora e como essa foi e continua sendo uma profissão feminina e de ascensão intelectual e social para diversas mulheres negras. Conceição Evaristo já relatou que seu contato com a escrita vem do desenho que sua mãe fazia do sol no chão. Como era lavadeira, sua mãe necessitava do sol para seu sustento, sendo esse traçado, no chão de terra batida, uma influência para os traçados posteriores de Conceição como professora, pesquisadora e escritora.

Assim, as escrevivências revelam corpos que se amontoam em memórias que denunciam as desigualdades sociais, raciais e de gênero, como revela outro fragmento: ['Curso superior não estava nos meus planos, achava impossível passar no vestibular e sinceramente nunca tentei fazer, aliás, nem dinheiro para pagar eu tinha e não conhecia ninguém que estava fazendo faculdade. Na minha cabeça faculdade era pra rico']. Além disso, as escrevivências também anunciam os desafios de ser mãe e universitária: ['Com meu filho já grande e estabilizada no serviço público, decidi fazer o Enem e fui aprovada em alguns cursos incluindo Pedagogia (...) confesso que não era uma das minhas opções, mas decidi agarrar essa oportunidade e hoje vejo que foi uma ótima decisão']. Apesar da existência de políticas públicas que impulsionaram e ainda impulsionam trajetórias acadêmicas de professoras negras, é preciso que identifiquemos que muito há a ser feito para que vejamos mais mulheres periféricas, negras e mães ocupando os bancos universitários. São indícios que emergem das escrevivências, escancarando realidades: ['Quando pequena sonhava em uma profissão que melhorasse a condição social de minha família. Meu pai sonhava que fizesse concurso para Justiça para que pudesse pedir transferência para Pernambuco, estado de origem de sua família'].

Como fomenta o ateliê biográfico de projetos, existe, ao final do ciclo de encontros, a produção de uma escrita autobiográfica com uma projeção de si para o futuro. Nessas escrevivências, a referida pesquisa identificou análises das participantes acerca de suas trajetórias, da construção de saberes docentes e reflexões sobre o curso de Pedagogia na contemporaneidade. Assim como as escrevivências de Evaristo (2006), as escrevivências aqui recuperadas mostram o passado e o presente misturando-se à esperança de um futuro que está por vir. Não falamos aqui de um futuro que está dado, mas sim de uma história que se escreve ao passo que se vive. Uma das participantes, 
professora negra da Baixada Fluminense traz em sua escrevivência final: [Daqui pra frente quero ser diferente... vou me inspirar em vocês e nos colegas para melhorar minha prática e oferecer o melhor de mim no futuro dos meus alunos, pois me sinto muito responsável e amada por eles]. Quantos saberes atravessam essa professora negra em seu processo formativo?

É possível que identifiquemos, no fragmento acima, que a pedagoga em construção concebe sua construção a partir do movimento dialógico, desenvolvido com seus pares e, também, o como anseia que seja o curso de Pedagogia espaço para o exercício da práxis. Portanto, podemos dizer que a escolha por metodologias autobiográficas é fundamentalmente formativa, ao passo que a pesquisa se constrói ao mesmo tempo em que também se constroem as narrativas de si. E isso acontece porque ao escrever suas escrevivências, essas mulheres negras e tantas outras, compreendem quem são... de onde vieram e pra onde irão... Assim, a escrevivência "devolve ao afrodescendente a sua origem pelo reconhecimento de seu passado" (EVARISTO, 2008, p. 4). Ao desvelarem suas memórias, desvelam também vivências, injustiças, desigualdades, desafios, des (encontros) que atravessam o debate sobre formação de professoras negras no Brasil.

\section{CONSIDERAÇÕES FINAIS}

Depreende-se, após análise do uso do ateliê biográfico de projetos e da compreensão de seus escritos autobiográficos como escrevivências, o potente papel de denúncia que tal escolha metodológica possui em pesquisas no campo da educação e especificamente em pesquisa sobre formação de professoras negras. As subjetividades que emergem das escrevivências dão conta de trazer para o debate de hoje questões que nos são muito caras na academia, mas que, por vezes deslocadas de suas enunciadoras, perdem seu caráter insurgente.

Quando Evaristo (2006) apresenta a escrevivência em Becos da Memória ela também nos apresenta um Brasil a partir do olhar de mulheres negras. Ela utiliza tal recurso, com uma intenção literária de subverter a ordem e de tornar protagonistas aquelas que por vezes são invisibilizadas. Por meio das escrevivências, as pesquisas acadêmicas também subvertem a ordem, debruçando-se sobre narrativas de mulheres negras para dialogar a respeito de diferentes temáticas.

É importante que se faça pesquisa sobre formação de professoras negras ouvindo a vida de professoras negras, compreendo suas memórias ancestrais e suas vivências. A construção de uma sociedade antirracista perpassa pela leitura da história de todas e todos. $O$ ato de biografar-se pela escrevivência oportuniza que outras histórias possam ser conhecidas e valorizadas. A escrevivência traz para o presente importantes pautas sociais (gênero, raça e condição) que atravessam 'o ser professora negra no Brasil' e que não podem ser menosprezadas quando pensamos em seus processos formativos.

Logo, conceber pesquisas a partir de metodologias que primem por escrevivências é ir de encontro aos discursos hegemônicos que silenciam o feminino subalterno. Esse movimento da literatura e da academia ressalta as dores e esperanças 
ROCHA, R. M.; AZEVEDO, P. B. de.

de um corpo, por meio de um lugar de enunciação novo: a mulher negra na 'vozprimeira'. Tal recurso metodológico fundamenta a escrevivência como um contradiscurso, uma subversão ao patriarcado e um 'soco no estômago' daqueles que teimaram em escrever a história por elas...

Artigo recebido em: 30/03/2021

Aprovado para publicação em: 14/10/2021

\begin{abstract}
THE NARRATING ABOUT HIMSELF AND WRITING: THE PLACE OF AUTOBIOGRAPHICAL WRITING IN RESEARCH ON THE FORMATION OF BLACK TEACHERS
\end{abstract}

ABSTRACT: This article aims to reflect on the contributions of autobiographical writing to the formative process of future black pedagogues, based on the analysis of methodological choices in the master's thesis of one of the authors. Thus, we discuss how the act of lining up DeloryMomberger's (2006) biographical project studio to the term Conceição Evaristo (2006)'s writings contributes to the formation of black teachers, having as a contribution to this reflection some evidence of that research. In it, black students from the Pedagogy course at the Federal Rural University of Rio de Janeiro are invited to narrate their formative trajectories through the act of biography, subverting order, in an intrinsically formative process. It appears, therefore, that the choice for such methodological paths is also configured as a space for denunciation, as it is developed in an attempt to unveil underground memories. In the movement of writing about themselves, black pedagogues under construction write about ancestral memories, for so long silenced, that emerge, in a space of research, through writing.

KEYWORDS: Autobiographical Narratives. Writing. Underground Memories. Training of Black Teachers.

LA NARRACIÓN SOBRE SÍ MISMO Y LA ESCRITURA: EL LUGAR DE LA ESCRITURA AUTOBIOGRÁFICA EN LA INVESTIGACIÓN SOBRE LA FORMACIÓN DE PROFESORES NEGROS

RESUMEN: Este artículo tiene como objetivo reflexionar sobre los aportes de la escritura autobiográfica al proceso formativo de los futuros pedagogos negros, a partir del análisis de elecciones metodológicas en la tesis de maestría de uno de los autores. Así, discutimos cómo el hecho de alinear el estudio del proyecto biográfico de Delory-Momberger (2006) con el término escritos de Conceição Evaristo (2006) contribuye a la formación de profesores negros, teniendo como contribución a esta reflexión algunas evidencias de esa investigación. . En él, se invita a estudiantes negros del curso de Pedagogía de la Universidad Federal Rural de Río de Janeiro a narrar sus trayectorias formativas a través del acto de la biografía, subvirtiendo el orden, en un proceso intrínsecamente formativo. Parece, por tanto, que la elección por tales caminos metodológicos se configura también como un espacio de denuncia, ya que se desarrolla en un intento de desvelar memorias subterráneas. En el movimiento de escribir sobre sí mismos, los pedagogos negros en construcción escriben sobre memorias ancestrales, silenciadas durante tanto tiempo, que emergen, en un espacio de investigación, a través de la escritura.

PALABRAS CLAVE: Narrativas Autobiográficas. Escritura. Recuerdos Subterráneos. Formación de Profesores Negros.

Inter-Ação, Goiânia, v.46, n.3, p. 1345-1359, set./dez. 2021. Disponível em: <http://dx.doi.org/10.5216/ia.v46i3.68429>. 
NOTAS

1 - De acordo com Delory-Momberger (2005) o exercício da biograficidade trata-se do poder que o indivíduo possui de biografar-se, narrando o próprio percurso de formação, reorganizando a memória das experiências vividas.

2 - É importante ressaltar que trabalharemos com o conceito de narrativa de si a partir da perspectiva do ateliê biográfico de projetos e sua compreensão da narrativa biográfica como processo formativo.

3 - De acordo com Delory-Momberger (2006) o 'contrato de participação' para início do ateliê biográfico pode ser assinado pelos participantes (modelo escrito) ou pode ser acordado apenas oralmente.

4 - O Ateliê biográfico de projetos prevê uma organização em tríades, onde aquilo que é dito deve ser registrado naquele exato momento, através da escrita. Essa biografização, que vai ao longo dos encontros ganhando novas linhas e parágrafos, não é gravada e nem tampouco existe no ateliê uma preocupação com a transcrição literal do que fora compartilhado. Por esse motivo o ateliê biográfico de projetos não se baseia na metodologia da História Oral, uma vez que não se fundamenta em entrevista (oralidade) e em sua gravação.

\section{REFERÊNCIAS BIBLIOGRÁFICAS}

ALVES-MAZZOTTI, A. J e GEWANDSZNAJDER, F. O método nas ciências naturais e sociais: pesquisa quantitativa e qualitativa. $2^{\text {a }}$ ed. reimp. São Paulo: Pioneira Thompson Learning, 2002.

BAKHTIN, M. Estética da criação verbal. São Paulo: Martins Fontes, 1992.

DELORY-MOMBERGER, C. Formação e socialização: os ateliês biográficos de projeto. Educação e Pesquisa, São Paulo, v. 32, n. 2, maio/ago. 2006.

\section{DELORY-MOMBERGER, C. Histoire de vie et recherche biographique en éducation.} Paris: Econômica, 2005.

EVARISTO, C. Becos da memória. Belo Horizonte: Mazza Edições, 2006.

EVARISTO, C. Escrevivências da afro-brasilidade: história e memória. Releitura, Belo Horizonte, n. 23, 2008. Disponível em: http://nossaescrevivencia.blogspot.com/2012/08/escrevivencias-da-afrobrasilidade.html. Acesso em: 23 mar. 2021.

EVARISTO, C. Da grafia-desenho de minha mãe, um dos lugares de nascimento de minha escrita. In: ALEXANDRE, Marcos Antônio (org). Representações performáticas brasileiras: teorias, práticas e suas interfaces. Belo Horizonte: Mazza, 2007, p. 16-21. 
ROCHA, R. M.; AZEVEDO, P. B. de.

FIORIN, J. L. Introdução ao pensamento de Bakhtin. São Paulo: Ática, 2008.

HALBWACHS, M. A memória coletiva. São Paulo: Ed. Centauro, 2006.

ROCHA, R. M. Memórias da (o) pedagoga (o): a construção docente pelas narrativas de alfabetização e letramento de estudantes da UFRRJ. 2020. f.138 Dissertação (Mestrado em Educação) - Programa de Pós- Graduação em Educação, Contextos Contemporâneos e Demandas Populares, Universidade Federal Rural do Rio de Janeiro. Rio de Janeiro, 2020.

POLLAK, M. Memória, esquecimento, silêncio. In: Estudos Históricos, Rio de Janeiro, vol. 2, no 3, 1989, p. 3-15.

Renata Melo Rocha: Mestra em Educação pela Universidade Federal Rural do Rio de Janeiro (2020). Pós-graduada em Psicopedagogia pela Universidade Cândido Mendes (2013) e Graduada em Pedagogia pela Universidade Federal Fluminense (2011). Formadora do Programa Federal - Pacto Nacional pela Alfabetização na idade certa (PNAIC) no biênio 2017-2018. Técnica em Educação pela Secretaria Municipal de Educação da cidade de Nova Iguaçu.

Orcid: https://orcid.org/0000-0002-7121-7931

E-mail: renatarosjm@gmail.com

Patrícia Bastos de AzeVedo: Possui graduação em Pedagogia (1995), graduação em História (1998) e mestrado em Educação pela Universidade Federal Fluminense (2003), doutora em Educação pela Universidade Federal do Rio de Janeiro (2011). Atualmente é professora Adjunta da Universidade Federal Rural do Rio de Janeiro. Orcid: https://orcid.org/0000-0003-1006-0253

E-mail: patriciabazev@gmail.com

Este periódico utiliza a licença Creative Commons Attribution 3.0, para periódicos de acesso aberto (Open Archives Initiative - OAI). 